\title{
Mechanical properties of the lung in extrinsic allergic alveolitis ${ }^{1}$
}

\author{
C. P. W. WARREN, K. S. TSE, AND R. M. CHERNIACK
}

From the Departments of Medicine and Immunology, University of Manitoba, the Respiratory Divisions, Clinical Investigation Units, Health Science Centre, and St. Boniface General Hospital, and the MRC Group for Allergy Research, Winnipeg, Manitoba, Canada

Warren, C. P. W., Tse, K. S., and Cherniack, R. M. (1978). Thorax, 33, 315-321. Mechanical properties of the lung in extrinsic allergic alveolitis. The lung function of 14 patients with extrinsic allergic alveolitis caused by exposure to mouldy hay (farmer's lung) or to birds (bird fancier's lung) was studied one week and four to six weeks after the last exposure to antigen. These data, together with lung mechanics measured four weeks after antigen exposure, were compared with measurements in 34 healthy non-smoking control subjects. Shortly after exposure to antigen there were reduction in lung volumes, increased elastic recoil (reduced compliance), and varied effects on expiratory flow and reduced gas transfer. With time, lung volumes and gas transfer improved, but expiratory flow often remained decreased. The data on lung mechanics showed that reduced compliance was often found, but this increased recoil did not always produce high airflow indicating increased upstream airways resistance. Patients with a longer duration of the illness tended to have increased compliance (reduced recoil) and low airflow. These results show that the described pathological changes of airway involvement, fibrosis, and emphysema in allergic alveolitis are manifest in the lung function of patients with the disease.

Extrinsic allergic alveolitis is a disease caused by hypersensitivity reaction in the lungs to inhaled organic material such as fungal spores or animal proteins. The clinical and radiological picture is varied and seems to depend on the quantity and duration of exposure to the antigen (Hapke $e t$ al., 1968). The pathology of allergic alveolitis shows that the alveoli, and to a lesser extent bronchioli, are infiltrated with lymphocytes and granulomata with giant cells. In advanced chronic disease fibrosis and sometimes emphysema are found (Seal et al., 1968). The immunological hallmark of the disease is the presence in the patient's serum of precipitating antibodies against the causative antigen (doPico et al., 1976; Faux et al., 1971). Restricted lung volumes are the common abnormality in allergic alveolitis (Hapke et al., 1968; Schlueter et al., 1969) but reduction in forced expiratory volume/forced vital capacity ratios $\left(\mathrm{FEV}_{1} / \mathrm{FVC}\right)$ have been reported and are thought to indicate airflow obstruction, sometimes associated with emphysema (Barbee et al., 1968;

'Supported by a grant from the Medical Research Council of Canada.
Schlueter et al., 1969). The object of this study was to investigate by measurements of lung mechanics the nature of airflow obstruction in allergic alveolitis.

\section{Methods}

The sex, age, radiological appearance, and mode of presentation of the 14 patients are given in Table 1. Only one patient (case 10) had ever smoked. Six patients had developed an acute illness of cough, dyspnoea, fever, and malaise; six had developed a subacute illness of progressive cough, dyspnoea, lassitude, and weight loss; and two patients presented with chronic dyspnoea. Two patients (cases 5 and 7) had had documented attacks of farmer's lung five and seven years earlier.

No subject reacted on prick testing with common antigens. Eight patients had farmer's lung, six had bird fancier's lung. Serum-precipitating antibodies against appropriate causative antigens were found in each patient. Inhalation of antigen 
Table 1 Anthropometric and clinical features of patients with extrinsic allergic alveolitis

\begin{tabular}{|c|c|c|c|c|c|c|c|c|}
\hline $\begin{array}{l}\text { Case } \\
\text { No. }\end{array}$ & Sex & Age & Antigen & $\begin{array}{l}\text { Radiography at time } \\
\text { of first study }\end{array}$ & $\begin{array}{l}\text { Duration of } \\
\text { symptoms } \\
\text { (months) }\end{array}$ & Mode of presentation & $\begin{array}{l}\text { Lung } \\
\text { biopsy }\end{array}$ & $\begin{array}{l}\text { Positive } \\
\text { inhalation } \\
\text { challenge }\end{array}$ \\
\hline $\begin{array}{l}1^{*} \\
2 \\
3^{*} \\
4 \\
5 \\
6 \\
7 \dagger \\
\\
8 \\
9 \dagger \\
10 \ddagger \\
11 \\
12 \S \\
13 \\
14\end{array}$ & $\begin{array}{l}\mathbf{M} \\
\mathbf{M} \\
\mathbf{M} \\
\mathbf{M} \\
\mathbf{M} \\
\mathbf{F} \\
\mathbf{M} \\
\mathbf{F} \\
\mathbf{M} \\
\mathbf{M} \\
\mathbf{F} \\
\mathbf{F} \\
\mathbf{M} \\
\mathbf{F}\end{array}$ & $\begin{array}{l}19 \\
22 \\
24 \\
25 \\
40 \\
41 \\
45 \\
\\
49 \\
52 \\
55 \\
56 \\
61 \\
62 \\
68\end{array}$ & $\begin{array}{l}\text { Hay } \\
\text { Chicken } \\
\text { Hay } \\
\text { Hay } \\
\text { Hay } \\
\text { Hay } \\
\text { Hay } \\
\text { Budgie } \\
\text { Hay } \\
\text { Hay } \\
\text { Budgie } \\
\text { Budgie } \\
\text { Pigeon } \\
\text { Budgie }\end{array}$ & $\begin{array}{l}\text { Diffuse nodular } \\
\text { Diffuse nodular } \\
\text { Diffuse shadowing } \\
\text { Normal } \\
\text { Diffuse nodular } \\
\text { Reticulonodular } \\
\text { Hyperinflated, } \\
\text { diffuse nodular } \\
\text { Diffuse reticulonodular } \\
\text { Diffuse reticular } \\
\text { Diffuse reticulonodular } \\
\text { Diffuse reticulonodular } \\
\text { Normal } \\
\text { Diffuse nodular } \\
\text { Diffuse shadowing, } \\
\text { small lung volumes }\end{array}$ & $\begin{array}{l}1 \\
2 \\
1 \\
1 \\
2 \text { and } 84 \| \\
24 \\
2 \text { and } 609 \\
4 \\
24 \\
1 \\
28 \\
24 \\
3 \\
18\end{array}$ & $\begin{array}{l}\text { Acute } \\
\text { Acute } \\
\text { Acute } \\
\text { Subacute } \\
\text { Acute on subacute } \\
\text { Subacute } \\
\text { Acute on chronic } \\
\text { Subacute } \\
\text { Chronic } \\
\text { Acute } \\
\text { Subacute } \\
\text { Chronic } \\
\text { Subacute } \\
\text { Subacute }\end{array}$ & $\begin{array}{l}\text { Yes } \\
\text { Yes } \\
\text { Yes } \\
\text { Yes }\end{array}$ & $\begin{array}{l}\text { Yes } \\
\text { Yes }\end{array}$ \\
\hline
\end{tabular}

*Brothers.

+ Brothers.

†Ex-smoker (1/day).

\$Steroid therapy four months before study.

\|Acute episode seven years before.

TAcute episode five years before.

produced typical changes in the five patients challenged. Alpha-l-antitrypsin levels, eosinophil counts, and total IgE concentrations were normal in all patients.

Lung biopsies were performed in five patients. These showed thickening of intra-alveolar septa and bronchiolar walls with lymphocytes, plasma cells, and occasional histiocytes, eosinophils, and giant cells. There was some evidence of fibrosis in septa and areas of partial obliteration of alveoli due to fibrosis (severe in case 14). There was hyperplasia of terminal and respiratory bronchiolar epithelium.

Only one patient (case 12) had had steroids, discontinued four months before the study.

\section{Respiratory measurements}

Forced vital capacity (FVC), maximum midexpiratory flow rate (MMF), and maximum expiratory flow rates ( $\mathrm{V}$ max) were measured using an automated wedge spirometer and were compared to the predicted values of Cherniack and Raber (1972). Functional residual capacity (FRC) was measured by the helium dilution technique, and total lung capacity (TLC) and residual volume (RV) were calculated and compared to the predicted values of Bates et al. (1962). The change in helium concentration during equilibration was monitored until no further fall occurred for one minute. Carbon monoxide extraction (CO extrn) was measured by the steadystate end-tidal technique of Bates et al. (1955) and compared to the predicted values of Goldman and Becklake (1959).

The compliance of the lung was measured by⿳亠丷厂 the method of Milic-Emili et al. (1964), analysis $\varrho$ of lung volume and related elastic recoil pressure $\overrightarrow{\vec{B}}$ being performed by analogue and digital com- 3 puter equipment (Connelly, 1971). Total airflow? resistance was determined by the method of Mead and Whittenberger (1952-53). Upstream resistance (RUS) was examined from the relation-응 ship between the elastic retractive force and $V \max$ at equivalent lung volumes (Mead et al., 1967). Data were also obtained in three groups of non-smoking asymptomatic persons; ten menô aged 20-25 years, ten men over 35 , and 14 women over 35. They were not exposed to hay or birdso at any time.

\section{Results}

The mean values of lung function tests, expressed 0 as percentage of predicted, in the patients at the $\mathrm{w}_{\mathrm{N}}^{N}$ two times together with those in the 34 controlo subjects are shown in Table 2 . The results in theo patients were compared with those in the control subjects using a $t$ test; the statistical significance? of differences between patients and controls is indicated. It can be seen that at one week there were highly significant reductions in TLC, FVC,,$\stackrel{\mathbb{\Omega}}{\Omega}$ MMF, and CO extraction and a significant re- $\mathbb{D}_{\circ}$ duction in FRC in the patients. Over the nextfour weeks lung volumes and gas transfer increased, although TLC, FVC, and CO extractiono 
Table 2 Mean and one standard deviations, all save $F E V_{1} / V C$ ratio expressed as percentage predicted, of lung function results in 34 healthy control subjects and patients at one week and four to six weeks after exposure to antigen. Highly significant and significant differences of patients from controls are indicated

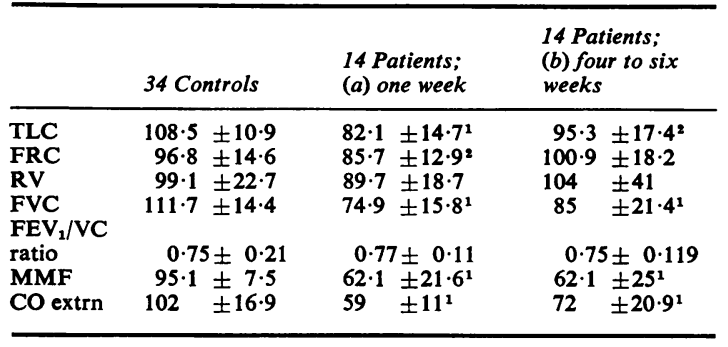

${ }^{1} \mathrm{P}<0.01$.

${ }^{2} P<0.05$.

remained significantly reduced. The mean MMF did not improve. Total lung resistance was normal in all save two patients at four weeks.

More detailed measurements of lung mechanics were made in three patients. At one week their pressure-volume curves (Fig. 1) were lower, indicating increased recoil at each lung volume (ie, a reduced compliance) compared with four weeks later. The changes in flow-volume (Fig. 2) over the four weeks varied. The static pressure flow relationships (Fig. 3) showed a definite decrease in upstream resistance in one patient (case 3).

The measurements of pressure-volume, flowvolume, and pressure-flow in all the patients are shown in Figs. 4, 5, and 6. The mean value \pm two standard deviations are shown for the control subjects, divided into three groups by age and sex. In Fig. 4 the pressure-volume curve was shifted to the right in four patients and up to the left in two.

In Fig. 5 the flow-volume measurements of the patients and controls are shown. Most patients had flow less than the mean for the controls, and in three subjects it was reduced below two standard deviations from the mearl.

Figure 6 shows the pressure-flow relationships in the patients and controls. In most patients the flow-pressure curves are flatter than those of the controls, and at higher pressure the flow is less than that of the controls by more than two standard deviations in several patients.

Total lung resistance was normal in all except two patients. Maximum inspiratory elastic recoil, elastic recoil at $60 \%$ of predicted TLC, and the compliance - that is, slope of the pressure-volume curve-over the tidal volume range are also shown in Table 3.

\section{Discussion}

The clinical presentation, chest radiographs, and immunological abnormalities in the patients suggest that the patients had extrinsic allergic alveolitis, while none had any evidence of asthma. The lack of chronic cough and phlegm production, the fact that all were essentially nonsmokers (Warren, 1977), and the normal alpha-1antitrypsin levels mean that coexistent chronic
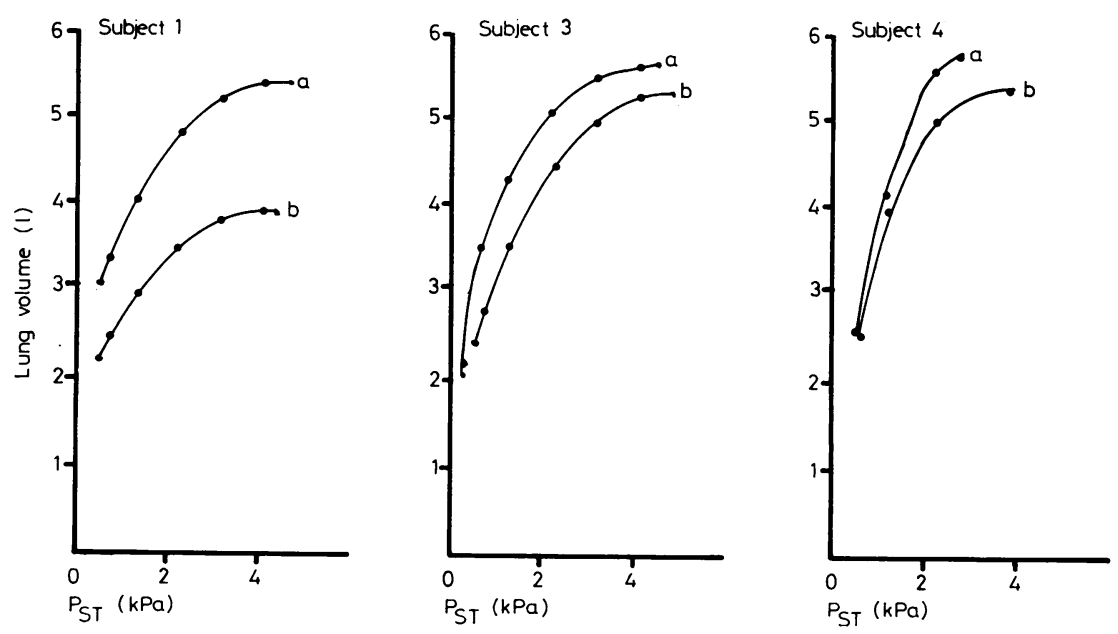

Fig. 1 Static pressure-volume characteristics in three patients with extrinsic allergic alveolitis at (a) one week and (b) four weeks. 


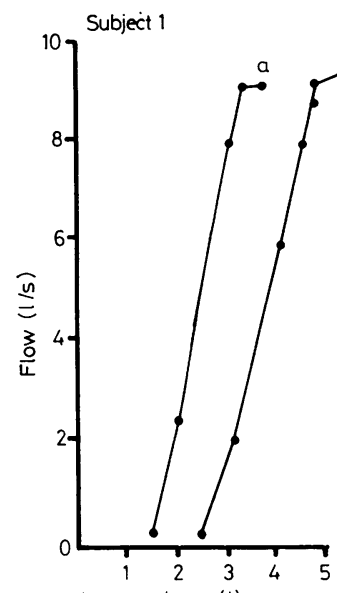

Lung volume (1)

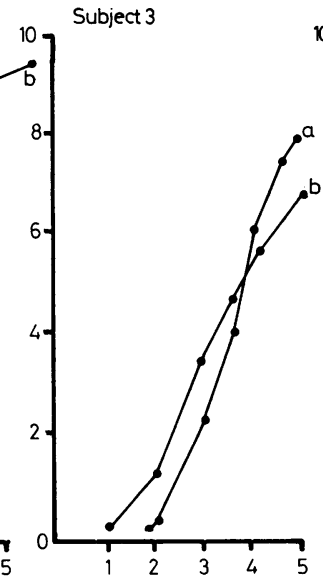

Lung volume (1)

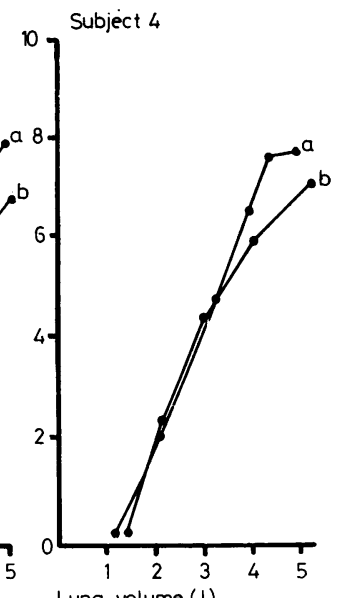

Lung volume (1)

to
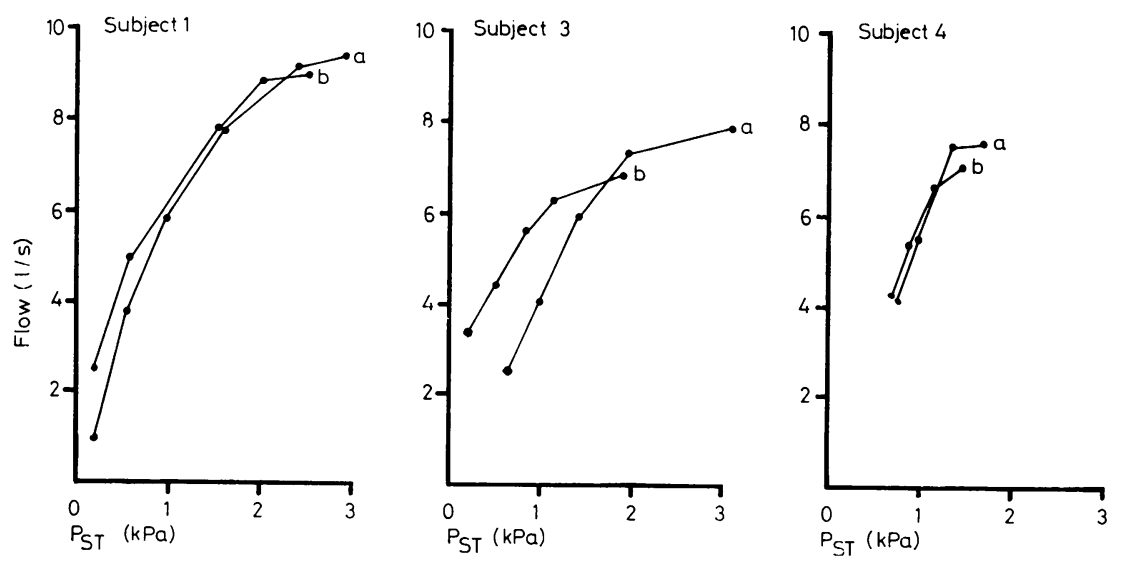

Fig. 3 Static pressure-flow relationships in three patients with extrinsic allergic alveolitis at (a) one week and (b) four weeks.
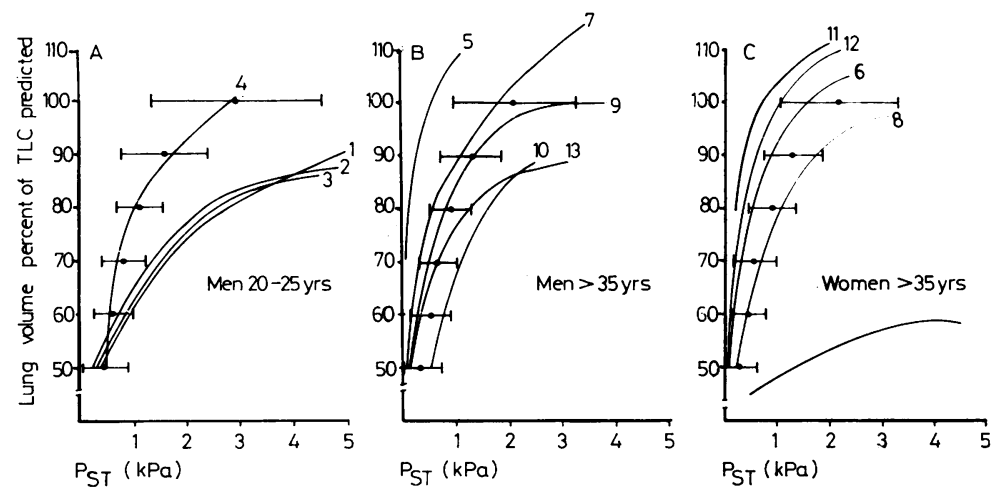

Fig. 4 Static pressure-volume characteristics in all patients with extrinsic allergic alveolitis at four to six weeks. Each patient is numbered. The mean and two standard deviations of healthy non-smoking individuals of equivalent age and sex are shown ( $m e n<25, n=10 ;$ men $>35, n=10$; women $>35, n=14$ ).

Fig. 2 Flow-volume relationships in $\stackrel{\circ}{-}$ three patients with extrinsic allergic (a) one week and (b) four weeks. 

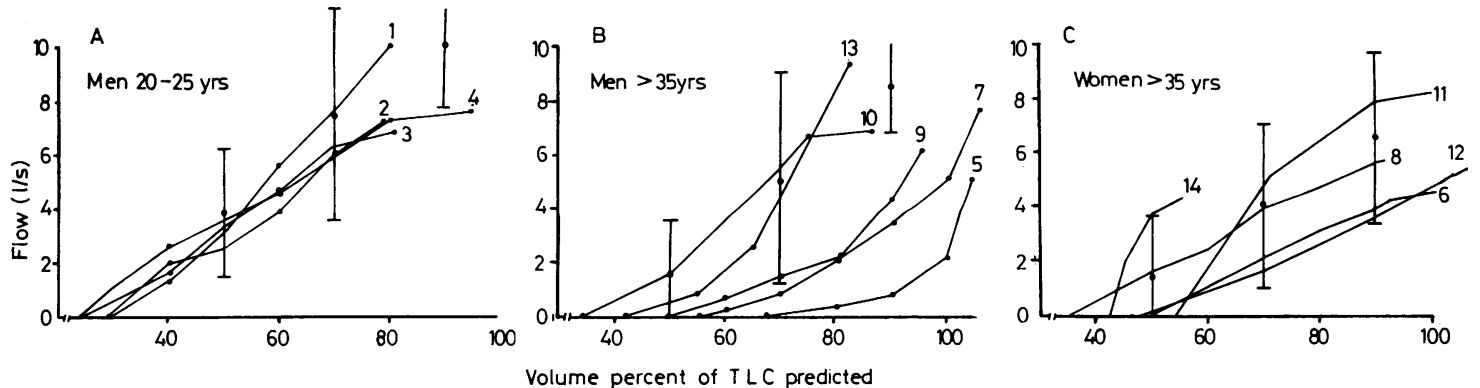

Fig. 5 Flow-volume relationships in all patients with extrinsic allergic alveolitis at four to six weeks. Mean and two standard deviations for healthy non-smoking individuals of equivalent age and sex as in Fig. 4 are shown.
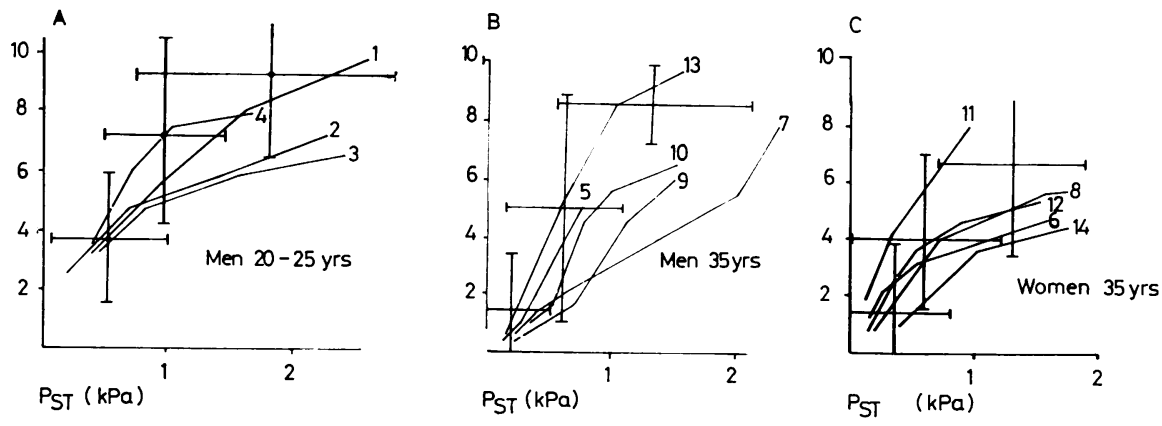

Fig. 6 Static pressure-flow relationships in all patients with extrinsic allergic alveolitis at four to six weeks. Mean and two standard deviations of healthy non-smoking individuals of equivalent age and sex as in Fig. 4 are shown.

Table 3 Measurements of maximum inspiratory elastic recoil, slope of expiratory pressure-volume curve at $F R C$, and total lung resistance in patients with allergic alveolitis at four to six weeks after last antigen exposure. Mean \pm two $S D$ in healthy control subjects also given

\begin{tabular}{|c|c|c|c|}
\hline Subject & $\begin{array}{l}\text { Max insp } \\
\text { elastic recoil } \\
\text { pst } \\
(\text { kPa })\end{array}$ & $\begin{array}{l}\text { Exp stat } \\
\text { compliance } \\
\text { at } F R C \\
\left(1 \mathrm{Ra}^{-1}\right)\end{array}$ & $\begin{array}{l}\text { Total lung } \\
\text { resistance } \\
\left(1 \mathrm{~s}^{-1} \mathrm{kPa}^{-1}\right)\end{array}$ \\
\hline $\begin{array}{l}\text { Controls } \\
\text { Mean } \pm 2 \text { SD } \\
\text { Men } 15-24 \text { years } \\
\text { Men }>35 \text { years } \\
\text { Women }>35 \text { years }\end{array}$ & $\begin{array}{l}3 \cdot 02 \pm 1 \cdot 6 \\
2 \cdot 02 \pm 1 \cdot 3 \\
2 \cdot 02 \pm 1 \cdot 3\end{array}$ & $\begin{array}{l}3 \cdot 6 \pm 2 \\
3 \cdot 3 \pm 1 \cdot 8 \\
2 \cdot 9 \pm 1 \cdot 2\end{array}$ & $\begin{array}{l}0 \cdot 13 \pm 0 \cdot 18 \\
0 \cdot 12 \pm 0 \cdot 198 \\
0 \cdot 19 \pm 0 \cdot 14\end{array}$ \\
\hline \multicolumn{4}{|l|}{ Patients } \\
\hline 1 & 4.9 & $1 \cdot 1$ & $0 \cdot 16$ \\
\hline 2 & $4 \cdot 8$ & $1 \cdot 3$ & $0 \cdot 17$ \\
\hline 3 & $4 \cdot 5$ & 1.4 & $0 \cdot 16$ \\
\hline 4 & 2.95 & $2 \cdot 7$ & 0.15 \\
\hline 5 & $1 \cdot 12$ & $6 \cdot 2$ & 0.36 \\
\hline 6 & $2 \cdot 6$ & 1.4 & $0 \cdot 12$ \\
\hline 7 & $3 \cdot 5$ & $2 \cdot 7$ & 0.24 \\
\hline 8 & $3 \cdot 4$ & $1 \cdot 3$ & $0 \cdot 17$ \\
\hline 9 & 4.0 & $2 \cdot 7$ & $0 \cdot 18$ \\
\hline 10 & $2 \cdot 15$ & $1 \cdot 6$ & $0 \cdot 17$ \\
\hline 11 & 1.8 & $2 \cdot 0$ & $0 \cdot 19$ \\
\hline 12 & $2 \cdot 4$ & $2 \cdot 2$ & $0 \cdot 13$ \\
\hline 13 & $3 \cdot 2$ & $3 \cdot \overline{2}$ & $0 \cdot 17$ \\
\hline 14 & $4 \cdot \overline{6}$ & 0.4 & 0.83 \\
\hline
\end{tabular}

airflow obstruction of other causes is unlikely. We conclude that all abnormalities of lung function detected in the study are likely to be the result of allergic alveolitis.

The study showed reduced lung volumes and impaired gas transfer in patients with allergic alveolitis after a recent exacerbation of their illness. Although the $\mathrm{FEV}_{1} / \mathrm{VC}$ ratio was usually normal, the MMF was reduced. The patients improved spontaneously with a gain in lung volumes and gas transfer but MMF remained low.

In the patients in whom the pressure-volume curves were shifted down and to the right it has usually been deduced that their lungs are stiff (less compliant) and hence lung volumes are reduced. Gibson and Pride (1977) have argued that this shift in the curve results from a loss of lung volume, fibrosis producing a patchy reduction in the number of normal alveoli rather than a uniform increase in stiffness of the lung. The resulting loss of lung volume would increase the mechanical advantage of the chest muscles and so produce the lower full inspiratory pleural pressures recorded. Their arguments are attrac- 
tive but morphometric studies are needed to confirm their hypothesis. Meanwhile, as in other studies of pulmonary alveolar fibrosis (Schofield et al., 1976; Ostrow and Cherniack, 1973; Jodoin et al., 1971) we believe that volume should be expressed as percentage of predicted TLC and that this provides a pressure-volume plot that shows the composite compliance of the lung. We do not think that the lung volumes measured by helium dilution misrepresented the true lung volume of the patients. This problem arises most frequently in patients with poor gas mixing, which is common in emphysema and slight in pulmonary alveolar fibrosis (Bates et al., 1971). The patients had ample time for equilibration with the helium. Any errors would be expected in hyperinflated patients and would produce an underestimate of volume and hence compliance; in restricted patients we expect the volumes were accurate, although possibly compliance was again underestimated. Our findings of loss of lung volume and compliance agree with the earlier findings in allergic alveolitis of Barbee et al., 1968. Schlueter et al., 1969, and Allen et al., 1976.

The less common abnormality of increased compliance (ie reduced elastic recoil) was consistent with the emphysematous changes found in the pathology of farmer's lung (Seal et al., 1968) and on chest radiographs of farmer's lung by Barbee et al. (1968). It has been reported in two patients with pigeon breeder's lung studied by Schlueter et al. (1969).

The flow-volume curves showed reduction of flow, particularly in patients with reduced elastic recoil. In those patients in whom lung elastic recoil was increased flows should also be increased unless resistance in the airways is high. When pressure-flow relationships were examined the slope of the curves was reduced in several patients, but in only three patients were they outside the normal distribution. This abnormality in the three patients indicates an increase in upstream resistance. The equal pressure point will be shifted upstream in these patients, and this increase in resistance to flow will not be apparent in measurements of total lung resistance or even $\mathrm{FEV}_{1}$. We suggest, as did Allen et al. (1976) that the increased upstream resistance in allergic alveolitis is situated in the small airways. The increased resistance was most evident at high recoil pressures when flows are highest and lung volumes largest. Lung biopsies showed cellular infiltration in the walls of small airways. It seems reasonable to postulate that these infiltrates may limit dilatation of the airways as lung volume increases, or result in turbulent airflow increasing resistance at high recoil. An increased upstreamis resistance has been reported in other causes of pulmonary alveolar fibrosis (Jodoin et al., 1971믈 Ostrow and Cherniack, 1973), but as in the study? by Gibson and Pride (1977) this may have beerp due to cigarette smoking. In allergic alveolitisu this cannot be the explanation. We and Allen et al. (1976) studied patients of whom all save? one were non-smokers.

Barbee et al. (1968) thought that reduced air. flow in farmer's lung was related to aging, al though they noted that men with this finding had a longer duration of symptoms. Hapke et al $l_{\hat{\omega}}^{\omega}$ (1968) and Schlueter et al. (1969) reported emphy sema in those with chronic disease, and our find $\vec{r}$ ings are similar; the patients with increasedg compliance had a long duration of illness as judged by history. It would appear that the acute inflammation of allergic alveolitis stiffens the lungs and that this damage may be repaired by fibrosis or result in cystic emphysematous spaces? as reported by Hargreave et al. (1972). The ${ }^{\infty}$ balance between fibrosis and emphysema wilb determine the overall function of the lung. That the decreased compliance (increased recoil) in many patients is not usually accompanied by thes expected increase in flow rates suggests some⿻ involvement in small airways by the disease pro $\overrightarrow{0}$ cess, a common pathological finding in the disease 3

We thank Mrs. M. Robertson for her invaluable technical help and Mrs. J. Young for secretarial help.

\section{References}

Allen, D. H., Williams, G. V., and Woolcock, A. J (1976). Bird breeder's hypersensitivity pneumonitis:o progress studies of lung function after cessation of exposure to provoking antigen. American Revieno of Respiratory Disease, 114, 555-566.

Barbee, R. A., Callies, Q., Dickie, H. A., and Rankin? J. (1968). The long-term prognosis in farmer's lung. American Review of Respiratory Disease, 97, 223231.

Bates, D. V., Boucot, N. G., and Dormer, A. E (1955). The pulmonary diffusion capacity in normak subjects. Journal of Physiology, 129, 237-252.

Bates, D. V., Macklem, P. T., and Christie, R. V (1971). Respiratory Function in Disease. W. B Saunders, Philadelphia.

Bates, D. V., Woolf, C. R., and Paul, G. I. (1962) Chronic bronchitis. A report on the first two stages of the co-ordinated study of chronic bronchitis $\overrightarrow{\mathbb{D}}$ Medical Services Journal of Canada, 18, 211-303.

Cherniack, R. M., and Raber, M. B. (1972). Norma $\mathbb{B}$ standards for ventilatory function utilizing ano automated wedge spirometer. American Review of Respiratory Disease, 106, 38-46. 
Connelly, N. (1971). Lungs: A program for real time or retrospective on-line analysis of certain physical properties of the human lungs. Computer Programs in Biomedicine, 1, 259-270.

doPico, G. A., Reddan, W. G., Chmelik, F., Peters, M. E., Reed, C. E., and Rankin, J. (1976). The value of precipitating antibodies in screening for hypersensitivity pneumonias. American Review of Respiratory Disease, 113, 451-455.

Faux, J. A., Wide, L., Hargreave, F. E., Longbottom, J. L., and Pepys, J. (1971). Immunological aspects of respiratory allergy in budgerigar (Melopsittacus undulatus) fanciers. Clinical Allergy, 1, 149-158.

Gibson, G. J., and Pride, N. B. (1977). Pulmonary mechanics in fibrosing alveolitis. The effects of lung shrinkage. American Review of Respiratory Disease, 116, 637-647.

Goldman, H. I., and Becklake, M. R. (1959). Respiratory function tests: Normal values at median altitudes and the prediction of normal results. American Review of Tuberculosis and Pulmonary Diseases, 79, 457-467.

Hapke, E. J., Seal, R. M. E., Thomas, G. O., Hayes, M., and Meek, J. C. (1968). Farmer's lung. A clinical, radiographic, functional and serological correlation of acute and chronic stages. Thorax, 23, 451-468.

Hargreave, F., Hinson, K. F., Reid, L., Simon, G., and McCarthy, D. S. (1972). The radiological appearance of allergic alveolitis due to bird sensitivity (bird fancier's lung). Clinical Radiology, 23, 1-10.

Jodoin, G., Gibbs, G. W., Macklem, P. T., McDonald, J. C., and Becklake, M. R. (1971). Early effects of asbestos exposure on lung function. American Review of Respiratory Disease, 104, 525535.
Mead, J., Turner, J. M., Macklem, P. T., and Little, J. B. (1967). Significance of the relationship between lung recoil and maximum expiratory flow. Journal of Applied Physiology, 22, 95-108.

Mead, J., and Whittenberger, J. L. (1952-53). Physical properties of human lungs measured during spontaneous respiration. Journal of Applied Physiology, 5, 779-796.

Milic-Emili, J., Mead, J., Turner, M., and Glauser, E. M. (1964). Improved technique for estimating pleural pressure from oesophageal balloons. Journal of Applied Physiology, 19, 207-211.

Ostrow, D., and Cherniack, R. M. (1973). Resistance to airflow in patients with diffuse interstitial lung disease. American Review of Respiratory Disease, 108, 205-210.

Schlueter, D. P., Fink, J. N., and Sosman, A. J. (1969). Pulmonary function studies in pigeon breeder's disease. Annals of Internal Medicine, 70, 457-470.

Schofield, N. McC., Davies, R. J., Cameron, I. R., and Green, M. (1976). Small airways in fibrosing alveolitis. American Review of Respiratory Disease, 113, 729-735.

Seal, R. M. E., Hapke, E. J., Thomas, G. O., Meek, J. C., and Hayes, M. (1968). The pathology of the acute and chronic stages of farmer's lung. Thorax, 23, 469-489.

Warren, C. P. W. (1977). Extrinsic allergic alveolitis: a disease commoner in non-smokers. Thorax, 32, 567-569.

Requests for reprints to: Dr. C. P. W. Warren, Department of Medicine, Clinical Investigation Unit, 3C St. Boniface General Hospital, Winnipeg, Manitoba R2H 2A6, Canada. 
function are presented in the table. The patient was restudied four months later, and the results with analgesics were very much the same.

\section{Comment}

Airways obstruction was strikingly relieved by aspirin in the patient studied. Similar beneficial effects were produced by three other cyclooxygenase inhibitors, that is, by indomethacin, mefenamate, and fenoprofen, but not by two remaining analgesics-salicylamide and benzydamine-which do not inhibit PG biosynthesis (Vane, 1976; Szczeklik et al, 1977). It was, therefore, logical to assume that the pharmacological removal of a product of arachidonic acid (AA) cyclooxygenation from his respiratory tract helped our patient to overcome the airways obstruction. Perhaps this product was a bronchoconstrictor $\mathrm{PGF}_{2} \alpha$, $\mathrm{TXA}_{2}$, or other as yet unknown metabolite. Whatever the metabolite was, it could not have been a physiological one, since we have found that bronchodilator $\mathrm{PGI}_{2}$ and $\mathrm{PGE}_{2}$ are two major products of AA transformation in the lungs (Gryglewski et al, 1978).

In our patient the suspected abnormality in arachidonate metabolism was restricted to the respiratory system. Detailed platelet function studies, particularly those related to arachidonic pathway, failed to show any differences from the normal. The transient petechiae were most likely due to increased vascular fragility secondary to triamcinolone administration.

The number of asthmatic patients who might benefit from aspirin is not known. Trial of aspirin treatment might seem warranted in asthma, since it could allow the steroid dose to be reduced, as in our case. Great care, however, would be necessary at the beginning of such treatment, and the initial dose of aspirin should not exceed $20-40 \mathrm{mg}$, as the same cyclo-oxygenase inhibitors, which proved to be so efficient in relieving bronchoconstriction in our patient, may produce bronchoconstriction in other asthmatics suffering from socalled aspirin-induced asthma (Szczeklik et al, $1975 ; 1977)$. Thus two opposite reactions can be caused in asthmatics by the same specific inhibitors. This indicates that different mediators, even derived from the same precursor, might play a different role in various types of asthma.

\section{Discussion}

Gryglewski, R J, Korbut, R, Ocetkiewicz, A (1978). Generation of prostacyclin by lungs in vivo and its release into arterial circulation. Nature, 273, 765767.

Szczeklik, A, Gryglewski, R J, and CzerniawskaMysik, G (1975). Relationship of inhibition of prostaglandin biosynthesis by analgesics to asthma attacks in aspirin-sensitive patients. British Medical Journal, 1, 67-69.

Szczeklik, A, Gryglewski, R J, and CzerniawskaMysik, G (1977). Clinical patterns of hypersensitivity to nonsteroidal anti-inflammatory drugs and their pathogenesis. Journal of Allergy and Clinical Immunology, 60, 276-284.

Szczeklik, A, Gryglewski, R J, Musial, J, Grodzińska, L, Serwońska, M, and Marcinkiewicz, E (1978). Thromboxane generation and platelet aggregation in survivals of myocardial infarction. Thrombosis and Haemostasis. (In press.)

Vane, J R (1976). The mode of action of aspirin and similar compounds. Journal of Allergy and Clinical Immunology, 58, 691-704.

Requests for reprints to: Dr A Szczeklik, Copernicus Academy of Medicine, Skawińska 8, 31-066 Cracow, Poland.

\section{Corrections}

1 Warren, C P W et al. Mechanical properties of the lung in extrinsic allergic alveolitis. Thorax, 1978, 33, 315-321.

The caption to figure 1 should show (a) four weeks and (b) one week.

2 Battesti, V P et al. Chronic cor pulmonale in pulmonary sarcoidosis. Thorax, 1978, 33, 76-84.

The authors regret that they omitted to acknowledge Professor J Turiaf, who originally studied the patients. 